\title{
Mesenchymal Paradigm: Implications in Morphogenesis
}

\author{
Gheorghe S Dragoi ${ }^{\star}$, Elena Patrascu, lleana Dinca and Petru Razvan Melinte \\ Department of Anatomy, University of Medicine and Pharmacy of Craiova, Craiova, Dolj, Romania \\ *Corresponding author: Gheorghe S Dragoi, Department of Anatomy, University of Medicine and Pharmacy of Craiova, lon Maiorescu Street 7, Craiova 200760, Dolj, \\ Romania, Tel: +040744547056; E-mail: dragoigs@gmail.com
}

Received date: September 24, 2016; Accepted date: December 15, 2016; Published date: December 19, 2016

Copyright: ( 2016 Dragoi GS, et al. This is an open-access article distributed under the terms of the Creative Commons Attribution License, which permits unrestricted use, distribution, and reproduction in any medium, provided the original author and source are credited.

\begin{abstract}
A micro-anatomic study of mesenchyme involvement in the morphogenesis of human biosystem is intended. The research was carried out on 80 sagittal serial sections taken from a 12-week human fetus. Spatial distribution of mesenchyme within the gut tube, urogenital and endocrine systems was analyzed. The results are based on the assumption that there are two forms of mesenchyme if one takes into consideration the embryonic origin: mesenchyme originating from mesoderm (meso-mesenchyme) and mesenchyme originating from ectoderm (ectomesenchyme) within the neural crest. We believe that in the morphogenesis of human biosystem, the mesenchyme can be induced byphenotype changes or it can act as an inductor in other structures. The significance of mesenchyme space distribution and of its phenotype changes in pathology is discussed.
\end{abstract}

Keywords: Meso-mesenchyme; Ecto-mesenchyme; Visceral stroma; Perivisceral fibrous structures

\section{Introduction}

Mesenchyma or mesenchyme, (Gr. mes=middle, Gr. enkyma=to infuse) is an embryonic tissue of mesodermal (Gr. meso-mesenchyma) or ectodermal (Gr. ecto-mesenchyma) origin. It plays a very important role in the structural genesis and evolution of the human bio-system. In the history of research the diversity of these mesenchymedependent structures raised numerous issues regarding the nomination of the embryonic conjunctive tissue, its morphogenesis and morpho-diferentiation and last, but not least, its regenerating capacity under normal and pathological conditions.

This is not a chance study. Since the introduction of the term mesenchyme by Hertwig et al. [1], the research regarding the mesemchyme has undergone two paradigmatic changes. The first model of paradigm was dominated by micro anatomic research methods; they enabled the evaluation of the mesenchymal role in the genesis and evolution of human biosystem structures [2]. Based on the criteria of its own genesis, two types of mesenchyme were identified: the mesenchyme derived from the mesoblast (meso-mesenchyme) and the mesenchyme derived from the ectoblast (ecto-mesenchyme).

Katschenko [3] observed that the mesenchyme from the cephalic region comes from the neural crest. Platt [4] proved that the mesenchyme within the bronchial arches is of ectodermal origin and her finding was confirmed by Landacre [5]. Along with the preoccupations for the identification of the ectodermal or mesodermal origin of the mesenchyme, numerous studies suggested the role of the interactions between epithelium and mesenchyme during the formation of bio-structures [6]. Cairns and Saunders [7] observed that the mesoderm possesses stimuli that induce the interaction between mesoderm and epithelium. Kollar and Baird [8,9] studied the epithelium-mesenchyme tissue interactions in the morphogenesis of teeth, attesting the influence of dental papillae on their growth.
The change of paradigm was imposed by the appearance of new research methods in the fields of developmental and cell biology; they enabled the discovery of "mesenchymal stem cells" by Friedenstein et al. [10], with implications in the regenesis of tissue and of the developmental genes involved in controlling cell proliferation, migration and differentiation.

Today we think it necessary to move on to a new paradigm in understanding the variable micro-anatomic involvement of the mesenchyme in morphogenesis and the embryo-fetal location of the structures derived from the mesoblast mesenchyme and/or ectoblast mesenchyme.

Our study is focused on the micro anatomic evaluation of the relations between the structures derived from the mesenchyme and the latter's localization within the abdominal cavity of a 12-week foetus. The following mesenchymal structures were analyzed: of the mesogastrium, mesentery and peri-visceral structures within the digestive and urogenital systems, as well as of the adrenal gland.

We consider might contribute to the enlightenment of the phenotypical transformations triggered by the involvement of the mesenchyme, both directly or as an inductor in the morphogenesis of biostructures in the process of epigenesis.

\section{Materials and Methods}

Our study was carried out on a 12-week-old human foetus that was spontaneously aborted, in the absence of any pathology of the mother. At the proximal extremity of umbilical cord, herniated ileal loops were present. The sex of the foetus could not be identified. The cephalic extremity did not present any malformations. The length vertexcoccygis was $72 \mathrm{~mm}$.

After washing it with saline solution, the fetus was introduced in 5\% formaldehyde solution buffered at $7.5 \mathrm{pH}$. After dehydration with ethanol and clarification with toluene, the fetus was embedded in paraffin. 
Page 2 of 4

We made 80 serial sections, 5 microns thick, following the sagital planes from lateral to medial. The sections were stained with Hematoxiline-Eosine. The microanatomic examination was performed with $\mathrm{x} 20, \mathrm{x} 40$ and $\mathrm{x} 60$ objectives of a Nikon Eclipse 80i microscope. The images were captured on Nikon Sight DS-Fil High Definition Color Camera Head and were processed by using Nis Element Advanced Research software.

\section{Results}

\section{Microanatomic analysis of mid gut mesenchyme structure in 12-week human foetus}

On examining these sagittal serial sections, with the objective $\mathrm{x} 4$, we identified the derivates of the primordium foregut caudal part (supraampular duodenum=Pars praeenteronica duodeni) and of the proximal limb of the midgut loop (infra-ampular duodenum=Pars mesenteronica duodeni, jejunum, ileum). Supra-ampular duodenum appears, on the sagittal sections, as having a semicircular shape, with dorsally oriented concavity. The dorsal part of the pancreas head is included in the duodenal concavity (Figure 1).

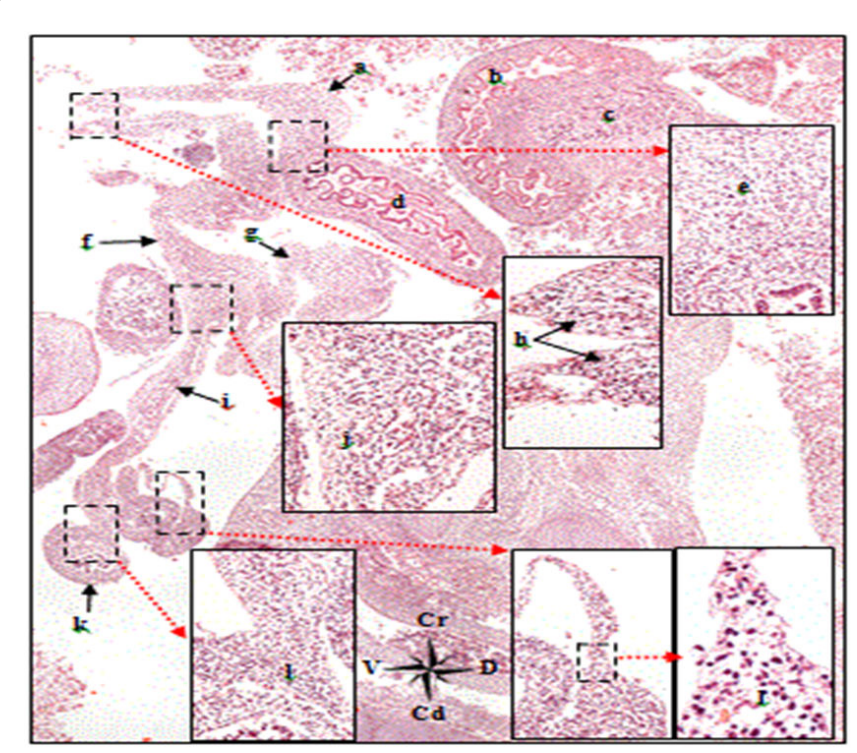

Figure 1: Microanatomic topography of mesenchyme inside the meso of midgut in 12 weeks human fetus; a: Mesoduodenum dorsale; b: Pars preenteronica duodeni; c: Pars dorsalis capitis pancreatis; d: Pars mezenteronica duodeni; e: Mesenchyme inside dorsal meso duodenum in relation to external layer of pars mesenteronica duodeni; f: Mesenterium dorsale commune; g: Mesojejunum; h: Vascular connective tissue inside dorsal mesoduodenum; i: Mesoileum; j: Mesenchyme inside mesenterium dorsale commune; $\mathrm{k}$ : Herniated ileal loops through umbilical orifice; 1: Mesenchyme inside mesoileum. Cr: Cranialis; Cd: Caudalis; V: Ventralis; D: Dorsalis. Paraffin section. Hematoxylin Eosine stain. Microphotographs taken with Nikon Sight DS-Fil High Definition Color Camera Head. Large image x4; Magnifier: $\mathrm{x} 10 ; \mathrm{x} 20$.

Infra-ampular duodenum appears, on the sagittal sections, as having an ovoid shape. Its external tunic continues with the mesenchyme of the mesoduodenum dorsale (Figure 1). When examining this mesenchyme, with the objective $\mathrm{x} 40$, the presence of numerous blood vessels surrounded by lax connective tissue is detected (Figure 1d). The mesoduodenal mesenchyme preserves a structure similar to the one of common dorsal mesentery: mesojejunum and mesoileum (Figure 1f, $1 \mathrm{~g}$ and 1i). On examination with the objectives $\mathrm{x} 10, \mathrm{x} 20$ and $\mathrm{x} 40$, we identified, within mesojejunum and meso-ileum, the same conjunctive-vascular structure as the one found at mesoduodenum level (Figure $1 \mathrm{~h}, 1 \mathrm{j}$ and $1 \mathrm{k}$ ).

\section{Microanatomic analysis of location, in structures derived from dorsal mesogastrium mesenchyme, in 12-week human foetus}

On examining the sagittal serial sections, with the objective $\mathrm{x} 4$, omental bursa appears as located retro-gastrically and delineated by mesenchymal structures, as follows: the external tunic of the gastric wall, the gastro-pancreatic ligament, the pancreatic-lienal ligament and gastro-lienal ligament. Ventral expansion of omental bursa is bordered by the gastro-pancreatic ligament (Figure 2). Dorsal mesogastrum mesenchyme contains the pancreatic bud, towards the ventral extremity of the pancreatico-lienal ligament (Figure 2d).

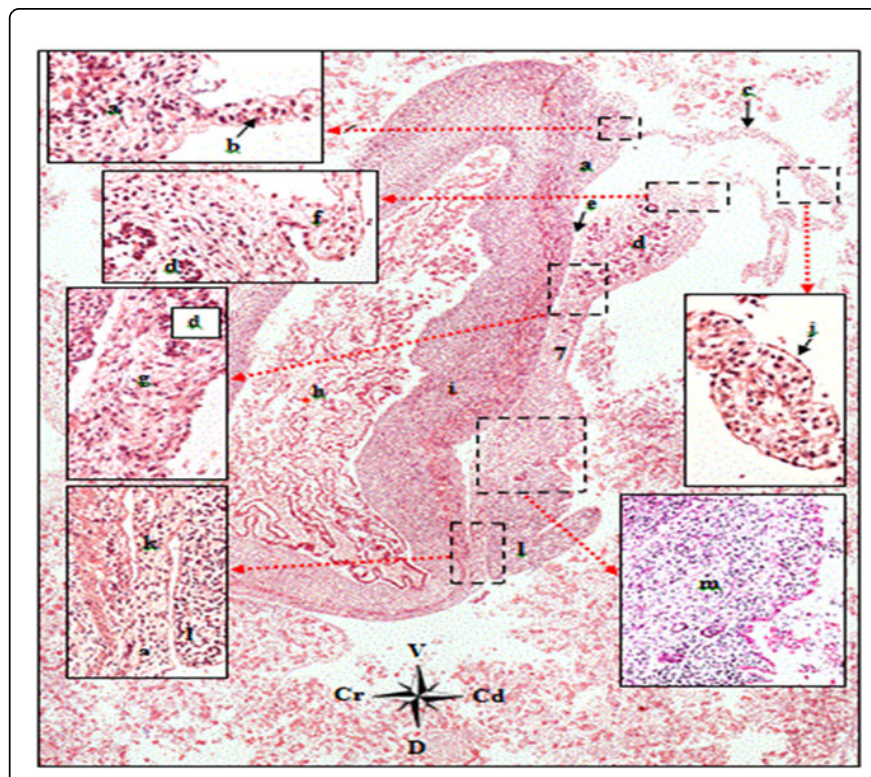

Figure 2: Differentation abilities of mesenchyme inside dorsal mesogastrum into pancreas stroma and lymphoid structures of spleen in 12 weeks human fetus. a: External tunic of gastric wall; b: Gastric insertion of gastropancreatic ligament;c. Gastropancreatic ligament; c: Dorsal pancreatic bud; d: Bursa omentalis; e: Pancreatic insertion of gastropancreatic ligament; f: Pancreaticosplenic ligament; g: Mucous tunic of stomach; h: Muscular tunic of stomach; i: Blood vessel forming mesenchyme; j: Gastrosplenic ligament; k: Lymphoid tissue primordia of spleen; l: Splenic insertion of pancreaticosplenic ligament. Cr: Cranialis; Cd: Caudalis; V: Ventralis; D: Dorsalis. Paraffin section. Hematoxylin Eosine stain. m: Microphotographs taken with Nikon Sight DS-Fi1 High Definition Color Camera Head. Large image x4; Magnifier : $\mathrm{x} 10 \mathrm{x} 20$. 
Within the dorsal mesogastrium extremity, we identified lymphoid structures belonging to spleen primordia. At this level, we visualized, with objectives $\mathrm{x} 20$ and $\mathrm{x} 40$, the primordia of spleen capsule, spleen reticular stroma and the origin of the gastro-lienal ligament (Figure $2 \mathrm{k}-2 \mathrm{~m})$. The connection between pancreatic and spleen primordia is made by a strong pancreatico-lienal ligament (Figures $2 \mathrm{~b}, 2 \mathrm{f}, 2 \mathrm{j}$ and $2 \mathrm{~m})$. On examining the dorsal mesogastrium mesenchyme, with objectives $\mathrm{x} 20$ and $\times 40$, a rich vascular network, containing haematicformator elements is visualized (Figures $2 \mathrm{~b}, 2 \mathrm{f}, 2 \mathrm{j}$ and $2 \mathrm{~m}$ ).

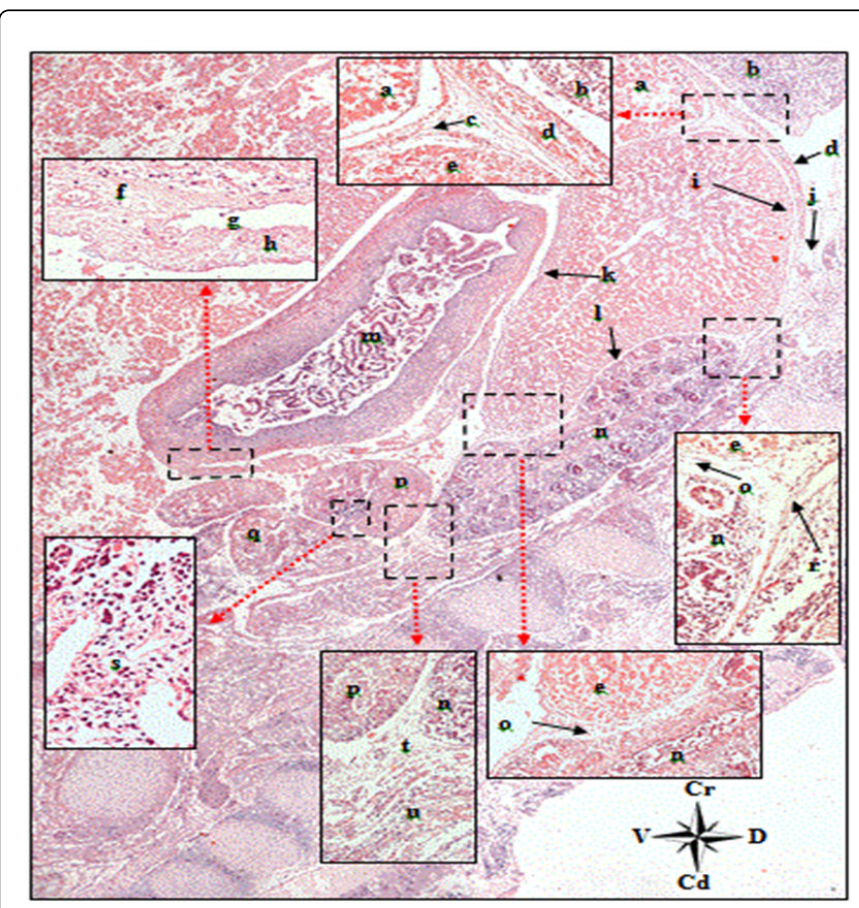

Figure 3: Microanatomic topography of mesenchyme inside suprarenal and urogenital systems in 12 weeks human fetus. a: Hepar - facies diafragmatica, pars superior; b: Basis pulmonis facies diaphragmatica; c: Subdiaphragmatic mesenchyme expansion between liver and suprarenal gland; d: Diaphragm; e: Glandula suprarenalis; f: External tunic of gastric wall; g: Bursa omentalis recessus inferior; h: Gastrosplenic ligament; i: Glandula suprarenalis - facies posterior; j: Recessus costodiaphragmatis; k: Glandula suprarenalis - facies anterior; l: Glandula suprarenalis - facies renalis; m: Gaster; n: Metanephros; o: Suprareno-renal mesenchyme expansion of renal capsule; p: Primitive gonad; q: Mesonephros; r: Perirenal fascia; s: Meso for primitive gonad; t: Fascia between primitive gonad, metanephros and psoas muscle. Cr: Cranialis; Cd: Caudalis; V: Ventralis; D: Dorsalis. Paraffin section. Hematoxylin Eosine stain. u: Microphotographs taken with Nikon Sight DS-Fi1 High Definition Color Camera Head. Large image x4; Magnifier: $\mathrm{x} 10$.

\section{Microanatomic analysis of perivisceral mesenchyme structures within the urogenital system, in a 12-week human foetus}

The examination of sagittal serial sections, with the objective $\mathrm{x} 4$, made visible structures derived from the mesenterium urogenitale mesoblast. Within the space delineated cranially by the diaphragm muscle, dorsally by the spine and ventrally by omental bursa, it is easily noticed the presence of the adrenal gland-of important sizemetanephros, the primitive gonad and mesonephros, in involutionary stage (Figure 3). Mesenchymal structures surround these viscera and are organized as capsules and intervisceral fibrous expansions. The adrenal gland is surrounded by a capsule-mesenchyme structure, through which it is in relation with the diaphragm, by facies dorsalis, with metanephros, by facies renalis and with omental bursa, by facies ventralis. In sagittal section, metanephros has an ovoid shape. The mesenchyme contributes to the formation of the renal capsule, through which metanephros is in relation with the adrenal gland through adreno-renal fibrous expansion (Figures 3o), with the primordial gonad, through a gonado-renal fibrous expansion and dorsally with the spine and psoas-iliac muscle, through a dorsal fibrous expansion of the renal capsule (Figures 3e, 3i, 3k, 3l, 3n, 3o and 3t). The primordial gonad maintains a connection with the mesonephros through the "primordial gonad meso" (Figure 3s). The gonad is surrounded by a perigonadal fascia, through which it is in relation with the psoas-iliac muscle (Figure $3 q$ and $3 u$ ).

\section{Discussion}

The mesenchyme remains a wide field of research due to its involvement in morphogenesis, re-genesis and tissue repair processes under normal or pathological conditions.

We made a micro anatomical analysis of the location of the mesenchyme within structures capable of growing and differentiating in time and space and within structures that limit compartments, such as visceral lodges.

The mesoderm mesnchyme within the mesentery was visualized and analyzed: a) at the insertion site of inter-visceral ligaments: gastric or pancreatic insertions of gastro-pancreatic ligament; pancreatic and splenic insertion of pancretico-splenic ligament; gastric and splenic insertions of gastro-splenic ligament; b) within the structures that fix the sub diaphragmatic digestive tube to the posterior abdominal wall: mesoduodenum dorsal, mesenterum dorsal commune, mesojejunum, mesoileum that are connected to the mesentery lymphatic system; c) within the perivisceral mesenchyme expansions: hepato-suprarenal, suprareno-renal, the fascia between the primitive gonad, metanephros and psoas muscle as well as in the meso of the primitive gonad.

The variability of the mesenchymal structures we analyzed is determined by the expression of tissue interactions such as: a) the mesenchyme originating in the mesoblast induces the morphogenesis of the mesentery of pancreas and gonads, of the perivisceral fibrous expansions, of the visceral stroma and last but not least, of the sub epithelial basal membrane; b) the mesenchyme originating in the ectoblast contributes to the morphogenesis of adrenal medulla together with the mesenchyme that determines the formation of adrenal cortex.

But, what is the significance of the mesenchyme spatial distribution and of its phenotype changes in pathology? Visceral stroma, as a form of mesenchyme distribution, offers information regarding the relations between epithelium and mesenchyme through the anatomic changes undergone by the sub-endothelial basal membrane. Stroma resists to the processes of putrefaction and can be visualized after reduced silver nitrate Gömöri method and/or after van Gieson picrofuxine staining. The presence of perivisceral fibrous expansions makes spaces that can be invaded by puss collections or haemorrhage. 
Citation: Dragoi GS, Patrascu E, Dinca I, Melinte PR (2016) Mesenchymal Paradigm: Implications in Morphogenesis. J Forensic Res 7: 358. doi:

Page 4 of 4

\section{Conclusion}

The mesenchyme is an omnipresent and pluripotent embrionary structure that is present in the morphogenesis and evolution of human biosystem structures. Today the change of paradigm is imposed as a need to analyze the variability of the morphogenesis of biostructures as a consequence of mesenchymal contribution in the dynamics of its epigenesis.

\section{References}

1. Hertwig O, Hertwig R (1881) Coelom theory. Attempting an explanation of the middle cotyledon. Fischer Publishers, Jena, Germany.

2. Minot CS (1879) Preliminary Notice of Certain Laws of Histological Differentiation. Proc Boston Soc Nat Hist 20: 202-209.

3. Katschenko N (1888) On the Developmental History of the Selachian Embryos. Anat Anz 3: 445-467.
4. Platt J (1893) Ectodermic Origin of the Cartilages of the Head. Anat Anz 8: 506-509.

5. Landacre FL (1921) The fate of the neural crest in the head of the urodeles. J Comp Neurol 33: 1-43.

6. MacCord K (2012) Mesenchyme. Embryo Project Encyclopedia.

7. Cairns JM, Saunders JW Jr. (1954) The influence of Embryonic Mesoderm on the Regional Specification of Epidermal Derivatives in the Chick. J Exp Zool 127: 221-248.

8. Kollar EJ, Baird RG (1969) The influence of the Dental Papilla on the Development of Tooth Shape in Embryonic Mouse Tooth Germs. J Embryol Exp Morphol 21: 131-148.

9. Kollar EJ, Baird RG (1970) Tissue Interactions in Embryonic Mouse Tooth Germs ; Reorganization of the Dental Epithelium during Tooth Germ Reconstruction. J Embryol Exp Morphol 24: 159-171.

10. Friedenstein A, Shapiro PI, Petrakova K (1966) Osteogenesis in Transplants of Bone Marrow Cells. J Embryol Exp Morphol 16: 381-390. 